\title{
LARGE-SCALE FIRE RISK PLANNING FOR INITIAL ATTACK AND FUELS: THE U.S. STATE OF IDAHO
}

\author{
DOUGLAS B. RIDEOUT ${ }^{1}$, NICOLE KERNOHAN ${ }^{1} \&$ JOE-RILEY EPPS ${ }^{2}$ \\ ${ }^{1}$ WESTFIRE Research Centre, \\ Department of Forest and Rangeland Stewardship, Colorado State University, USA. \\ ${ }^{2}$ Department of the Interior, Bureau of Land Management, USA.
}

\begin{abstract}
Public officials charged with managing the risk of wildland fire are looking for ways to apply risk analysis at large scales affecting a wide range of resources, including life and property. The ability to address risk analysis at a large scale is just now emerging with new technologies and analytics in such applications as STARFire. This paper summarizes how the STARFire planning and budgeting system were applied across the state of Idaho, and how it can be used to support state-wide planning using the Idaho State Fire Management Plan initiative as an example. The STARFire planning and budgeting system generated a large-scale risk analysis across the entire state of Idaho for the United States Department of Interior's Bureau of Land Management (BLM). The STARFire analysis is driven by a single performance metric 'return on investment' to make efficient use of scarce funding. We collaborated with officials at the BLM to identify and assemble key spatial input data such as: a full range of values at risk, fire behaviour and fire history, and fire management cost information. This and related information was analysed using the STARFire spatial planning and budgeting system to produce a state-wide risk analysis, an integrated fuels and initial attack analysis and an integrated budget analysis across programs. The analysis demonstrated the ability to assess BLM lands across the state and scale between the state and the associated planning units within the state. This is the first time that such an analysis has been performed at such a large scale (across multiple landscapes) at the program level. The associated planning unit level analysis was validated with BLM officials. Products support the BLM's first state-wide spatial fire management planning initiative
\end{abstract}

Keywords: economics, Fire Management Plan, fuel treatment, Idaho, landscape analysis, risk, spatial planning, STARFire, U.S. Bureau of Land Management, wildland fire.

\section{INTRODUCTION}

U.S. Federal land management agencies are charged with managing wildland fire to protect human life and valuable resources while promoting ecosystem viability. Federal fire management plans (FMPs) summarize wildfire management goals, objectives, and provide implementation guidance including a decision framework for coordinating wildland fire management on these lands [1]. In 2002, the federal Interagency Fire Planning Committee developed an Interagency Fire Management Plan (IFMP) to ensure FMPs were consistent across agencies. The IFMP was adopted as the FMP standard [2] to be used across federal agencies. In 2009, following consecutive decades of escalating extreme wildfire behavior that increased risk to life and property while expanding wildfire program costs, the US Congress mandated development of a National Cohesive Wildland Fire Management Strategy (NCWFMS) [3]. The strategy concluded with the 2014 National Action Plan [3]. The NCWFMS broadly defines a set of fire planning guidelines including restoring and maintaining fire-resilient landscapes wile considering wildfire risk, managing values at risk, and appropriate response to wildfire (how wildfire is best managed to promote healthy ecosystems and to protect life and property) [3]. The National Action Plan establishes the framework for implementation of actions and tasks at various scales [3]. This series of events left the federal agencies with uncharted challenges for implementing a new generation of fire planning. 
United States Department of the Interior (DOI) responded in 2014 by issuing a policy memorandum identifying that the IFMP template 'no longer provides the flexibility to adapt to shifting agency fire program priorities, organizations, and technology' [2]. Consequently, DOI fire planners developed a new FMP framework that incorporates the goals of the NCWFMS and includes the ability for FMP information to be presented in spatial and digital format. In 2015, the DOI's Bureau of Land Management (BLM) issued an Instruction Memorandum requiring existing IMFPs to be converted to the new FMP format established by the DOI [4]. This new direction presented new challenges with respect to scale, spatial analysis, data management and spatial technology.

With the new direction, the BLM undertook its first state-wide FMP in 2015 by using the state of Idaho as its first application. By extension, spatial scalability and the inclusion of current science were identified as foundational in meeting the new challenge and they were embraced [1]. Spatial scalability is essential to the BLM's state-wide FMP as the state is managed through a collection of smaller planning units known as 'districts'. Further, the US DOIs Washington Office of Policy Analysis [5] established expectations for fire planning including the use of a common performance metric and the use of sound economic or benefit cost analysis. To address the new goals including those of the NCWFMS, the BLM selected the spatial fire and planning and budgeting system called STARFire (Strategic Analysis of Risk in Fire) that was specifically designed for such purposes.

The STARFire spatial planning and budgeting system was developed in collaboration with the DOI's National Park Service (NPS), Fish and Wildlife Service, and the BLM at the WESTFIRE Research Center at Colorado State University [6]. STARFire integrates fire behaviour information, fire affected resource information and management cost information to generate spatial outputs based on the common performance metric known as return on investment (ROI). STARFire also addresses the critical programmatic trade-offs between fuels and initial attack programs (preparedness) for budget analysis. This paper summarizes how the STARFire planning and budgeting system was applied across the state of Idaho, how it can be used to support state-wide FMPs using the Idaho State Fire Management Plan (IDSFMP) initiative as an example. It embodies the new foundational planning criteria established by the DOI and the BLM.

\section{OBJECTIVES}

This research demonstrates the application of STARFire for addressing the new planning challenges embodied by the IDSFMP while informing federal budgets at the scale of a state. The state of Idaho application is shown to support planning and budgeting analysis while addressing current policy goals and demonstrating how the results can be used to inform federal budgets. The following objectives were addressed.

1. Generate a wildfire risk analysis to address the goals of the NCWFMS and to identify where wildfire is expected to produce the greatest loss to fire-affected resources and where managed fire can generate ecosystem benefit.

2. Inform the strategic location of fuels treatments to aid planners in prioritizing and optimizing hazardous fuel reduction while improving ecosystem function.

3. Provide a state-wide program level budget analysis to guide districts and the state office.

4. Generate a series of intermediate spatial products to support the IDSFMP.

\section{THE STATE OF IDAHO AND ITS BLM DISTRICTS}

The BLM manages about 14 million acres of range and forest land across the state. This constitutes 'one of the largest and most complex fire programs in the BLM.' [7]. The BLM 

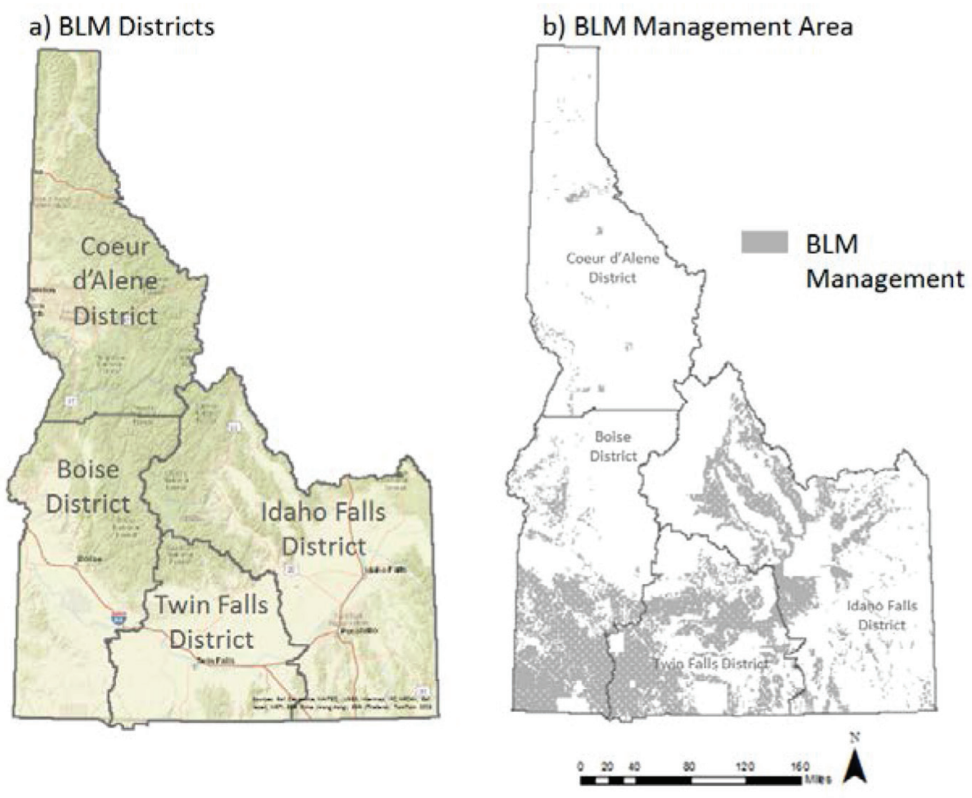

Figure 1: (a) Panel a - BLM Districts within the state of Idaho. (b) Panel b - the area within each district managed by the BLM. This analysis pertains to BLM lands.

divided the state into four management units called 'districts'. The districts are Coeur d'Alene (CDA), Boise (BOI), Twin Falls (TWF) and Idaho Falls (IDF) (Fig.1, panel a.). The area within each district that is managed by the BLM is displayed in Fig. 1, panel b.

\section{STARFIRE INPUTS AND MODULES}

The STARFire planning and budgeting system was applied to the State of Idaho by integrating fire behaviour and economics [6]. The analysis is driven by a common performance metric 'return on investment' (ROI) where value added through fire management planning is compared with the cost of fire management effort in a probabilistic, or stochastic, framework. An overview of the STARFire modules and inputs follow.

\subsection{STARFire modules}

STARFire is an integrated fire planning and budgeting system that contains three key modules: 1. Risk Assessment, 2. Fuel Treatment and 3. Program Budgeting. The Wildfire Risk Assessment shows where ignitions would cause varying degrees of expected loss or benefit across the entire landscape [8]. The Fuel Treatment analysis identifies the locations on the landscape that would provide the highest ROI if treated [9]. These are prioritized by budget level. The Program Budgeting module evaluates the entire suite of fuels and initial attack actions to generate efficient combinations of fuels and initial attack programs [10]. For example, the Program Budgeting module assesses the effects of the fuel treatments including their ability to reduce fire intensity and the spread rates of future wildfires. Reduced spread rates improve the ability of the firefighting operation to successfully contain fires during initial attack, while lower fire intensities often reduce expected losses. Further, fires contained in 
initial attack are typically less costly than those requiring extend attack operations. STARFire quantifies the effect of fuels treatment on initial attack.

\subsection{STARFire inputs}

The STARFire Wildfire Risk Analysis and the STARFire Fuel Treatment Analysis use three core datasets. The first includes fire behaviour information, the second considers the resources affected by fire (both positively and negatively), and the third includes management costs. The STARFire Program Analysis requires an additional preparedness dataset. Many of these inputs required intermediate processing steps and generated useful planning products to address objective 4 . All geospatial inputs collected for the Idaho analysis were converted into raster format. A cell size of $480 \mathrm{~m}$ (approximately 57 acres) was implemented to holistically process the large landscape.

\subsubsection{Fire behaviour}

National Fire Danger Rating Areas (NFDRA) is used by US federal agencies to represent geographic areas of relatively contiguous climate, fuels and topography. There are 25 NFDRA's in the state of Idaho and we used FlamMap (v5.0) [11] to estimate the fire behaviour for each NFDRA. Relevant weather conditions were acquired for each representative NFRDA weather station(s) and imported into FireFamily Plus [12] to summarize the 80th percentile weather scenario for wind direction, wind speed, dead fuel moistures ( 1 hour, 10 hour, 100 hour) and live fuel moistures (live herbaceous and live woody). Additional FlamMap inputs (fuel model, aspect, canopy bulk density, canopy base height, canopy cover, canopy height, elevation and slope) were acquired from LANDFIRE (v1.4.0) [13]. Several grass and shrub fuel models in the LANDFIRE data were updated to better reflect current conditions. The resulting FlamMap outputs for each NFRDA were aggregated together to generate one state-wide raster for each FlamMap output including flame length $(\mathrm{m})$, heat/unit area $\left(\mathrm{BTU} / \mathrm{ft}^{2}\right)$, rate of spread $(\mathrm{m} / \mathrm{min})$ and spread direction (degrees). Fire history data includes fire perimeters and ignition locations. Fire history data were obtained from the BLM for the state of Idaho. Ignition history was selected for the state of Idaho from data downloaded from the Spatial Wildfire Occurrence Data for the years 1992-2013 [14].

\subsubsection{Fire-affected resources}

BLM district resource managers were tasked with identifying fire-affected resources based on Land Use Plans and supplying the associated spatial layers. BLM subject matter experts were convened to estimate the magnitude of the fire effect on the resource values using the non-market and non-monetized economic valuation system known as MARS (Marginal Attributes of Substitution) [15]. This required assessing values by fire intensity and resource condition. Flame height was used as a proxy for establishing relative values by fire intensity and the amount of time since last fire was used as a proxy for the resource condition. Managers identified 211 fire affected resources and their rates of substitution (relative values). Fire affected values included those that are negatively impacted by fire (developments, infrastructure, cultural resources, vegetation types, watersheds, threatened and endangered species, and wildlife habitat) and resources that are improved by fire such as wildlife habitat. A summative depiction of the resource values are displayed in Fig. 2. 
a) Resources Positively Affected by Fire

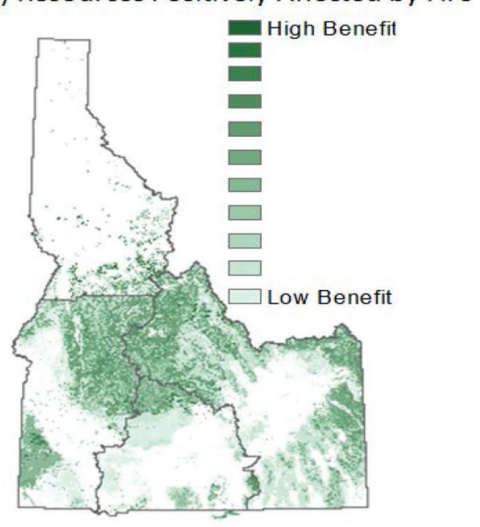

b) Resources Negatively Affected by Fire

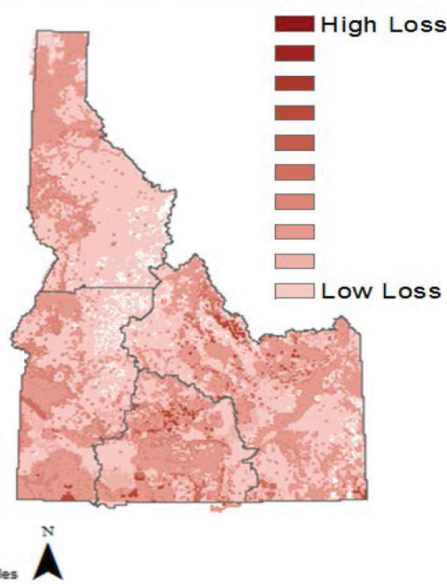

Figure 2: (a) Panel a - Resources improved by fire. (b) Panel b - Resources negative affected by fire. Darker colours represent areas with a higher benefit or loss.

\subsubsection{Management costs}

Including the cost of fuels treatments is essential to locating fuels treatments that would maximize the ROI to make the best use of the limited budget. Cost drivers were identified by treatment type and resource condition. Treatment types were correlated to a fuel model. Resource condition was identified by 'degraded' and 'intact'. Degraded areas require more expensive initial treatments. Intact areas require less expensive maintenance treatments. The 'degraded' and 'intact' areas were identified using the fire history inputs and the number of years since it has been since an area has received fire. Cost coefficients were then estimated by BLM officials using historical contracting averages and summarized in Table 1 .

\subsubsection{Preparedness inputs}

STARFire's preparedness module assesses the ability of the initial attack system to reduce the probability that fire will continue beyond initial attack. The probability of containing fire within the initial attack standard requires several inputs. The first set of inputs supports the estimation of how close in distance (converted to time) an ignition cell is to its nearest dispatch location. Ground dispatch locations for the state of Idaho were provided by the BLM. Travel time was estimated using ESRI's 'Cost Path' tool using the dispatch locations and a BLM supplied travel cost surface. The second set of inputs supports calculations for fire spread rates that are made by the fire behaviour model known as FlamMap. Third are inputs

Table 1: Relative fuel treatment costs by treatment type and resource condition.

\begin{tabular}{llll}
\hline Treatment type & Fuel model & Relative cost of degraded & Relative cost of intact \\
\hline Annual & $1-118$ & 320 & 160 \\
Sagebrush & $120-139$ & 150 & 75 \\
Juniper & $140-159$ & 200 & 100 \\
Timber & $160-209$ & 500 & 250 \\
\hline
\end{tabular}


used to calculate the probability of fire reaching beyond initial attack. Here, historical fire perimeters supported our estimates of the number of fires exceeding the initial attack acre limit. The initial attack acre limits varied across the landscape and were provided by the BLM. The final preparedness input reflects the intensity of the preparedness effort applied. This was reflected by a series of preparedness budgets provided by the BLM.

\subsection{STARFire analysis}

The Wildfire Risk Assessment (objective 1), Fuel Treatment analysis (objective 2), and Program analysis (objective 3) were performed in the STARFire system. The risk assessment was conducted across the entire Idaho landscape ( 54 million acres). The fuel treatment and program analysis were restricted to the area managed by the BLM ( 14 million acres). Fuel treatments were selected across a range of budgets $(\$ 5,999,045 ; \$ 9,988,658 ; \$ 15,000,000$ and $\$ 19,997,046)$ and preparedness was applied at 8,15 and 20 million-dollar budgets. The value added to the landscape from each fuel treatment budget level and each preparedness budget level was recorded by district and used in the program analysis. A translog production function was fit to the data for each district and used as a means of interpolating between the modelled budget levels. A path of steepest value-added ascent was estimated using combinations of preparedness and fuels budgets

\section{STARFIRE OUTPUTS}

The outputs from the STARFire analysis are discussed for the risk assessment, and fuel treatment selection and program analysis.

\subsection{Wildfire risk assessment (Objective 1)}

A STARFire Wildfire Risk Assessment was generated for the Idaho landscape (Fig. 3, panel a). It shows the expected value of wildfire for any cell igniting on the landscape. Green

a) Wild Fire Risk

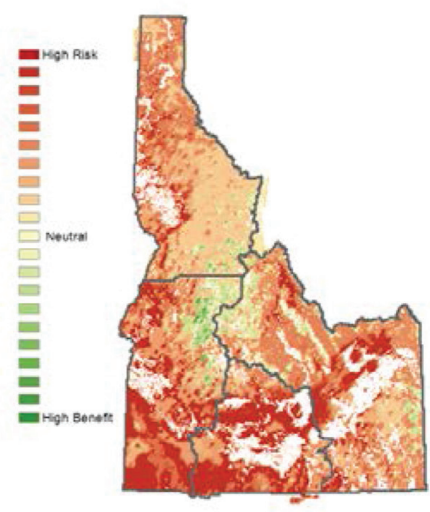

b) Return on Investment in BLM Managed Areas

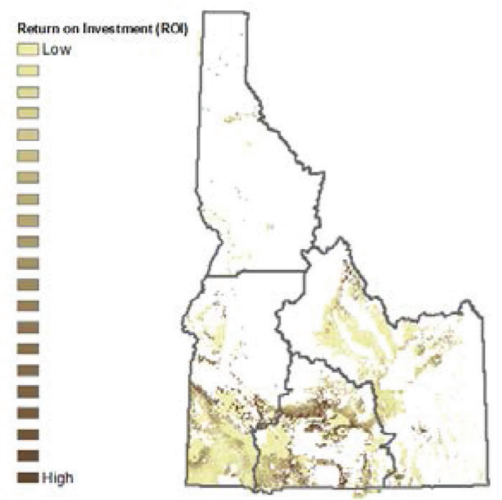

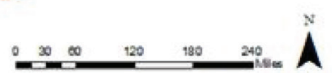

Figure 3: (a) Panel a - Wildfire Risk - areas in red represent high risk of loss from wildfire and green area provide ecosystem benefit if burned. (b) Panel $b$ - return on investment in BLM managed areas. Darker colours represent areas that would generate a higher ROI from fuel treatment. 
areas indicate cells that would produce a positive expected outcome if burned and red cells indicate a negative, or detrimental expected outcome. Darker colours indicate greater impacts. The Wildfire Risk Analysis shows that most of the Idaho landscape is at risk from wildfire.

\subsection{Prioritizing fuel treatments (Objective 2)}

The STARFire Fuel Treatment analysis was generated for the BLM managed areas on the Idaho landscape to create a ROI surface (Fig. 3, panel b). Areas that are darker in colour represent areas on the landscape that would generate a higher ROI from fuel treatment. Fuel treatments were selected at each budget level to produce the highest ROI (Fig. 4, panel a) across the state within the BLM managed areas. The largest amount of treatment acres across all budget levels occurred in the Twin Falls district, followed by the Boise district. A smaller set of treatment acres occurred in the Coeur D'Alene district and the least amount was selected in the Idaho Falls district (Fig. 4, panel b). The post-treatment surface was compared with the pre-treatment surface to estimate the expected value added by budget level and district.

\subsection{Program analysis (Objective 3)}

The program analysis is presented for the districts and then for the state. The data points collected for each fuel treatment budget level and each corresponding preparedness budget level are used in the program analysis to interpolate a surface of value added for any combination of fuels and preparedness budgets. Fuel treatment and preparedness applications were blind to district allocations and boundaries to promote ROI across the state.

\subsubsection{District analysis}

To estimate the value-added surfaces by district, value-added for each fuel treatment and preparedness budget combination was summed across the corresponding BLM cells by district. Implied budgets were calculated for the preparedness and fuels programs. Using the implied preparedness budget, implied fuel budget, and value-added data for each district, a

a) Fuel Treatment Location by Budget

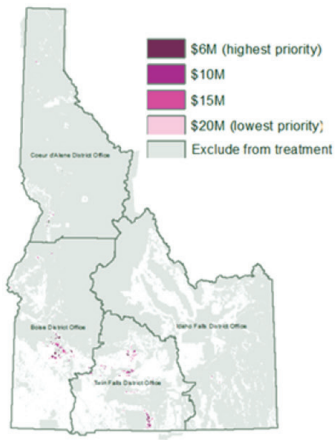

b) Acres Treated by District and Budget

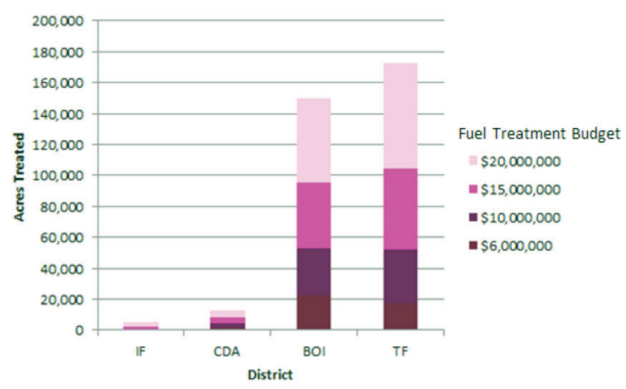

Figure 4: (a) Panel a - Fuel Treatment selection by budget level - the highest priority treatment acres (smallest budget) are depicted by the darkest pink colour and the least priority acres (largest budget) are depicted by the lighter pink colours. The grey area represents areas that were excluded from selection. (b) Panel b-indicates the number of acres selected by district and budget increment. 

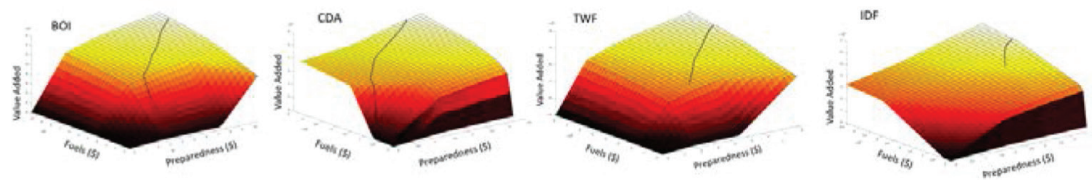

Figure 5: Paths of steepest ascent overlaid on the production surface for each district in the state of Idaho.

new surface was interpolated. Fig. 5 shows all possible combinations of preparedness and fuels budget and their respective value-added estimates. STARFire's Program Analysis applies a gradient-based approach that gradually changes the budget allocation between the fuel treatment and preparedness programs across the districts to generate a path of steepest value-added ascent. This approach avoids sharp budget changes that may be disruptive to the entire program. These paths are shown for each district by the black line in Fig. 5. The paths start from the current district budget allocations for preparedness and fuels and identify the combinations of preparedness and fuels budgets that yield the greatest value- added as the funding increases.

The proportion of the district budget allocated to each program is depicted in Fig. 6. The preparedness portion is represented in blue and fuels proportion is represented in orange. The $\mathrm{x}$-axis represents the total budget for the district in millions of dollars. This is the sum of preparedness and fuels budgets for each district at each point on that districts path. The district's current budget is the starting point on the x-axis. The y-axis shows the fuels and preparedness proportion of the total district budget.

\subsubsection{State analysis}

The total state budget is the sum of all preparedness and fuels budgets for all four districts.
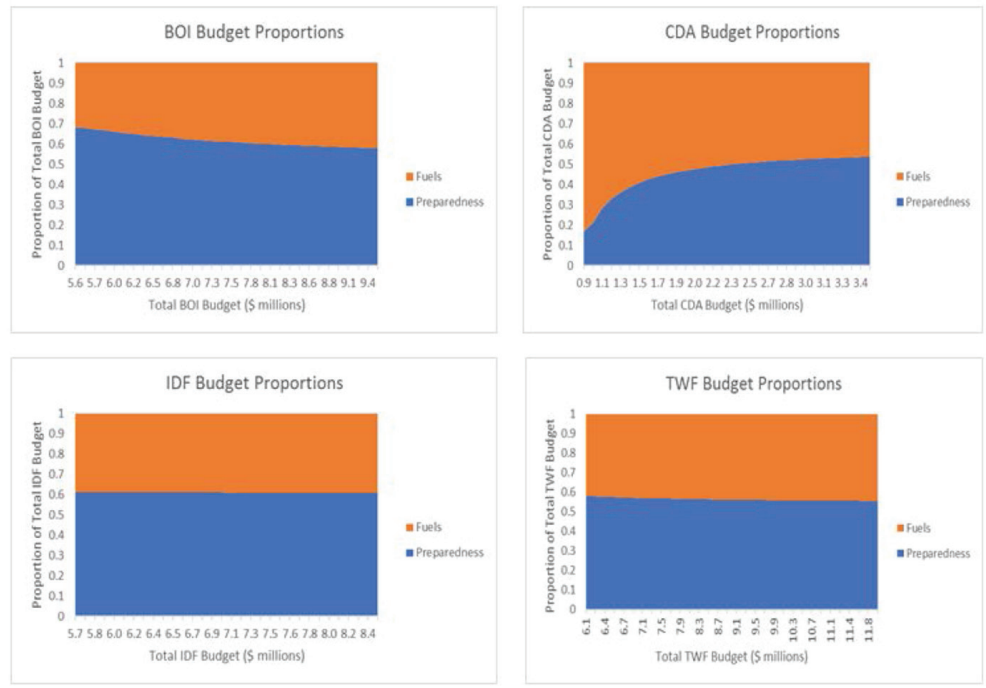

Figure 6: Program budget proportions for each BLM district in the state of Idaho. 
a) State Budget Proportions

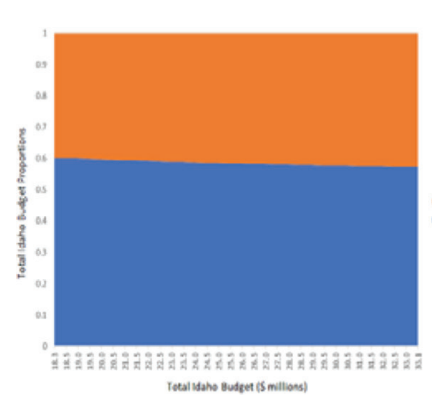

b) District Proportions within State

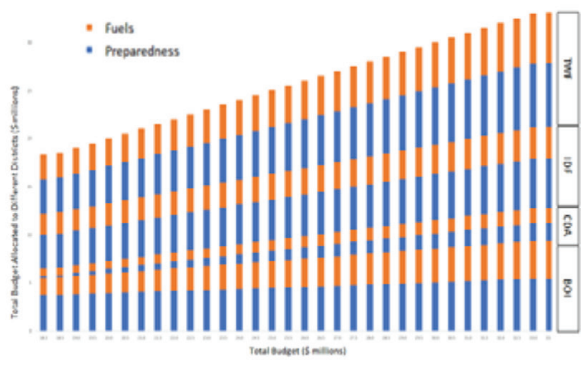

Figure 7: (a) Panel a - Proportion of state budget allocated to preparedness and fuels for different levels of state budget. (b) Panel b - Dollars allocated to each program within each district.

Panel (a) in Fig. 7 shows the proportion of budget for the fuels and preparedness programs and panel (b) shows the budget allocation to each district by program across the full range of total budgets.

\section{STARFIRE AND THE IDAHO STATE FIRE MANAGEMENT PLAN}

The IDSFMP consists of a formal written FMP document and an interactive web map that complements the IDSFMP. Both the IDSFMP document and interactive web map support the IDSFMP's four broad categories; (i) Introduction, Policy and Land Management Planning, (ii) Fire Management Goals and Objectives, (iii) Wildland Fire Operational Guidance and (iv) Monitoring and Evaluation as well as the sub-categories within. The IDSFMP is currently in a formal review process [16].

\subsection{IDSFMP document}

The purpose of IDSFMP is 'to describe the Idaho State Directors leader's intent, program objectives and to provide strategic and operational guidance as identified through existing land use plans' [16]. The STARFire analysis was extensively used in the IDSFMP document. The Branch of Fire \& Aviation Management at the Idaho State Office (ISO) is responsible for providing budget allocation to the district's fire programs [16]. The STARFire Program Analysis (objective 3) was used in the 'Program Organization' subsection to support the Program Overview and inform budgeting decisions. A summary of the above STARFire analysis was also documented in the 'Science' subsection with the corresponding literature references for each of STARFire analysis modules.

\subsection{IDSFMP interactive web map}

The Interactive Web Map spatially displays information and reduces re-stating information by linking to other sources of digitally available data and information [4]. The IDSFMP Interactive Web Map is built on ESRI's Story Map platform [17]. Story Maps provide the ability to combine maps with narrative content as demonstrated by Fig. 8.

The IDSFMP Interactive Web Map provides the spatial support for each section in the IDSFMP document. STARFire's Wildfire Risk map (objective 1) was used in the 'Fire Management Goals and Objectives' section to provide visual support for the 'Wildland Fire Related Resource and Protection Objectives' sub-section as depicted in Fig. 9. 


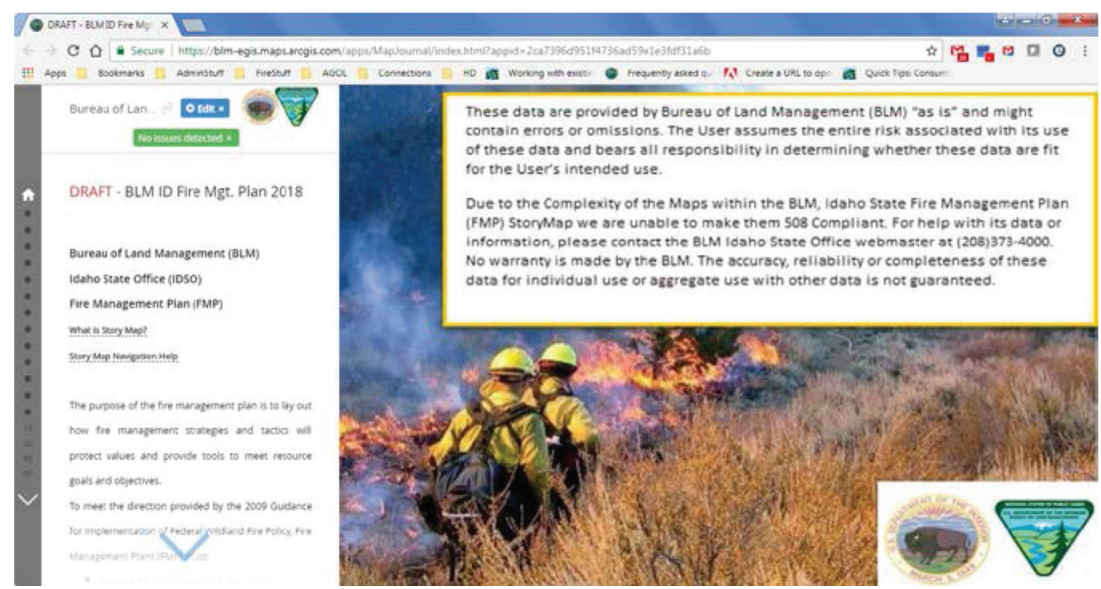

Figure 8: Screen shot of the draft version of the IDSFMP interactive web map based on ESRI's story map platform.
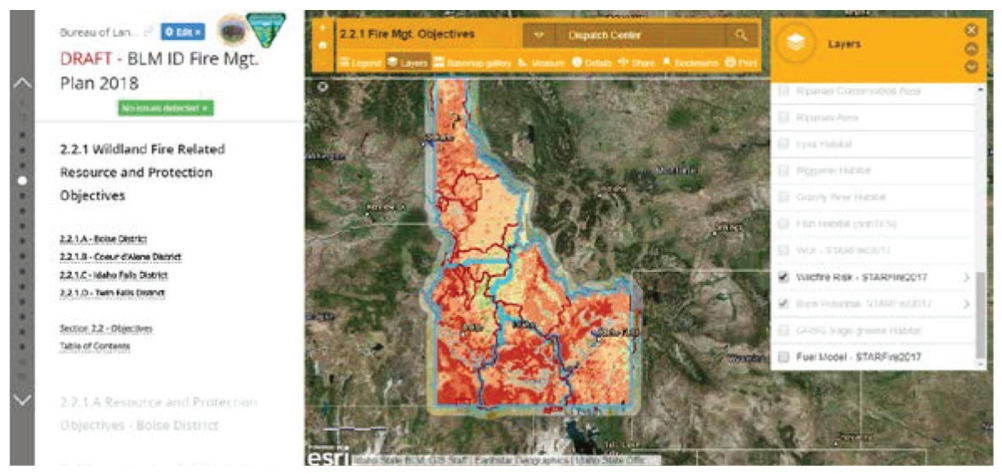

Figure 9: Screen shot of the draft version of the IDSFMP Interactive Web Map and STARFire's integrated wildfire risk map.
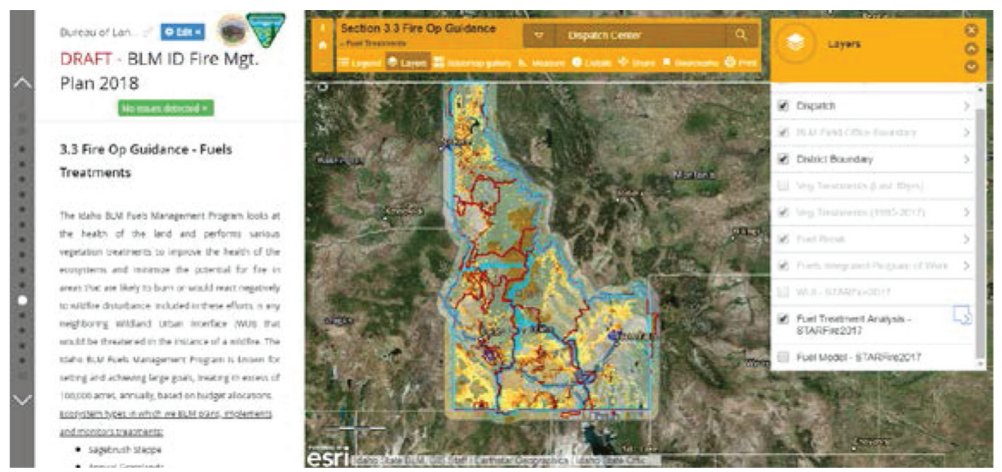

Figure 10: Screen shot of the draft version of the IDSFMP Interactive Web Map and the integration of STARFire's fuel treatment analysis. 
STARFire's Fuel Treatment Analysis (objective 2) was included in the 'Wildland Fire Operational Guidance' to support the 'Fuels Treatment' subsection (Fig. 10). Many of the other intermediate STARFire products (objective 4) were included as supporting maps throughout the IDSFMP.

\section{CONCLUSIONS}

The Idaho BLM STARFire application represents a state-wide fire management planning effort across a full spectrum of values and integrated programs that embodies the new BLM planning criteria. This application met the four main objectives for supporting a new Fire Management Plan initiative and current policy guidelines. The STARFire wildfire risk analysis quantified risk across the landscape and the appropriate response to wildfires based on values at risk while the fuel treatment analysis identified optimal treatments to reduce risk. In combination these analyses address the goals outlined in the National Cohesive Wildland Fire Management Strategy. The STARFire Program Analysis was applied at two geographic scales, both district level and state level. A common performance metric (ROI) integrated within the STARFire system consistently evaluated the interaction of the Idaho BLM fuels and preparedness programs and guided optimal funding decisions for the state and its districts. The system addressed the economic considerations identified by the USDOI Office of Policy Analysis and in the NCWFMS.

\section{REFERENCES}

[1] Meyer, M.D., Roberts, S.L., Wills, R., Brooks, M. \& Winford, E.M., Principles of effective USA federal fire management plans. Fire Ecology, 11(2), pp. 59-83, 2015.

[2] USDOI, United States Department of Interior. OWF Policy Memorandum 2014-005. Online, available at https://elips.doi.gov/ELIPS/0/doc/4084/Electronic.aspx (accessed 6 June 2018).

[3] US Department of the Interior and US Department of Agriculture (USDOI and USDA). The national strategy: Final phase in the development of the National Cohesive Wildland Fire Management Strategy. 93 pages. Online, available at https://www.Forests andrangelands.gov/strategy/documents/strategy/CSPhaseIIINationalStrategyApr2014. pdf, 2014 (accessed 6 June 2018).

[4] USDOI. Instruction Memorandum No. FA IM-2015-028. Online, available at https:// www.frames .gov/files/1414/3500/1068/FA_IM 2015028.pdf (accessed 21 June 2018).

[5] USDOI Office of Policy Analysis. Wildland Fire Management Program benefit-cost analysis: A review of relevant literature. US Department of the Interior, Office of Policy Analysis, Washington, DC., USA. Online, available at https://www.doi.gov/ sites/doi. gov/files/migrated/ppa/upload/Wildland_fire_literature_review_060812FINAL.pdf, 2012 (accessed 21 June 2018).

[6] Rideout, D.B., Wei, Y., Kirsch, A. \& Kernohan, N., STARFire: Strategic budgeting and planning for wildland fire management. Park Science, 32(3), pp. 34-41, 2017.

[7] DOI Bureau of Land Management (BLM) Online, available at www.blm.gov/programs/ public-safety-and-fire/fire-and-aviation/regional-info/idaho (accessed 5 February 2018).

[8] Rideout, D.B. \& Wei, Y., A probabilistic landscape analysis supporting the management of unplanned ignitions at sequoia and king canyon national parks. Journal of Sustainable Forestry, 32(5), pp. 437-455, 2013.

[9] Rideout, D.B. \& Kernohan, N., The relative value of fire planning alternatives. Modelling, Monitoring and Management of Forest Fires III, eds. C.A. Brebbia and G. Perona, WIT Press: Boston, MA, 2013. 
[10] Wei, Y., Rideout, D.B., Kirsch, A.G. \& Kernohan, N., Science-based budgeting for National Fire Programs. WIT Transcactions on Ecology and the Environment, 10, pp. 107-113, 2017.

[11] FLAMMAP. Online, available at https://www.firelab.org/flammap (accessed January 2016).

[12] Bradshaw L. \& McCormick E., FireFamily Plus user's guide, Version2.0 Gen. Tech. Rep. RMRS-GTR-67WWW. Ogden, UT: U.S. Department of Agriculture, Forest Service, Rocky Mountain Research Station, 2000.

[13] LANDFIRE. Online, available at www.landfire.gov (accessed December 2015).

[14] Short, K.C., Online, available at https://www.fs.fed.us/rmrs/science-spotlights/spatialwildfire -occurrence-data-united-states-1992-2013, 2014 (accessed 22 January 2016).

[15] Rideout, D.B., Ziesler, P.S., Kling, R., Loomis, J.B. \& Botti, S.J., Estimating rates of substitution for protecting values at risk for initial attack planning and budgeting. Forest Policy and Economics, 10(4), pp. 205-219, 2008.

[16] USDOI Bureau of Land Management (BLM) Idaho State Office (IDSO) State Fire Management Plan (SFMP). Pending publication, 2018.

[17] ESRI. Online, available at https://storymaps.arcgis.com/en/ (accessed 21 June, 2018). 